\title{
High school students' experience of online learning during Covid-19: the influence of technology and pedagogy
}

\author{
Anne Yates (D), Louise Starkey $($ Den Egerton $(D)$ \& Florian Flueggen(iD)
}

\begin{abstract}
The Covid-19 pandemic resulted in New Zealand schools closing and teaching occurring through digital media. This paper reports research which applied Kearney et al.'s (2012) framework as a lens to examine student experience of digital learning at home during Covid19. This framework provides three characteristics that influence learners' experience when using digital devices for learning: personalisation, authenticity and collaboration. High school students in their final two years of schooling $(n=1975)$ responded to a questionnaire consisting of quantitative and qualitative questions with qualitative data analysed thematically and quantitative data with descriptive statistics. This study found aspects of Kearney et al.'s framework reflected in participants' experience and identified further important characteristics that influenced learning. Authenticity and collaboration facilitated learning, but participants valued supportive pedagogies and motivational strategies which enabled academic progress and enhanced wellbeing. Effective use of technology mediated supportive pedagogies and an alternative framework was developed to incorporate these additional findings.
\end{abstract}

\section{Introduction}

Over the last few decades digital technologies have been introduced into schooling and is changing the context of teaching and learning with increasing access to devices, the Internet, online learning environments and collaboration tools (Selwyn et al., 2017) resulting in varying degrees of integration or infusion of digital technology within schooling systems (Starkey, 2020). When the Covid-19 pandemic swept the globe, the New Zealand government initiated a policy to contain and eliminate community transmission of the virus, which required people to isolate at home. Schools closed on $25^{\text {th }}$ March 2020, teachers were given two weeks to prepare for online, remote teaching and learning which continued until $18^{\text {th }}$ May 2020 when schools re-opened. The New Zealand Ministry of Education supported this by: 
- providing online resources across three websites.

- trying to ensure all students, and in particular those in their final years of schooling, had internet access and a device for learning.

- broadcasting two television channels.(Education Review Office, 2020)

Two contextual aspects of the New Zealand education system influence this study. Firstly, New Zealand has a decentralised education system whereby decision-making such as pedagogical practices and the purchase and use of resources (e.g. educational technology) are devolved to individual schools and teachers (Wylie, 2012). This creates a range of practices from schools that have infused digital technologies across aspects of teacher professional practice, to others where access is limited (Starkey, 2020). Secondly, senior high school students undertake the National Certificate in Educational Achievement (NCEA) qualifications. NCEA consists of both external, end-of-year examinations, and school-based assessments completed during the school year. There is a strong focus in achieving these qualifications (Hipkins et al., 2016) and schools and teachers have considerable flexibility in how they implement NCEA such as which subjects are offered, which topics are taught, how they are taught and which assessments students are prepared for.

While online and distance learning are not new this was a novel and sudden experience for students who normally attend school. The timing was two months into the start of the academic year and the students were studying towards final school qualifications. As schools and teachers in New Zealand have professional flexibility there is likely to have been variety of pedagogical practices and technological use during remote learning. Therefore, this research explored how technology and pedagogy influenced senior student experience of learning during Covid-19. We hoped to identify effective, technology mediated pedagogical practices from the students' perspectives.

\section{Theoretical Framework}

Kearney et al. (2012) proposed a framework when using mobile devices (e.g. smart phones, tablets and laptops) for learning which provides three pedagogical characteristics that influence learners' experiences when using such devices: personalisation, authenticity and collaboration. Personalisation refers to learners accessing customised activities which can lead to a sense of ownership and to control over the time, place and pace at which they learn. Authenticity provides opportunities for contextualised, situated learning and through the use 
of digital devices students can generate asks involving participation in real-life practices and/or highly relevant learning activities. Collaboration is the conversational and connected aspects of online learning as technology allows a 'high level of networking' (p. 10).

Collaboration also refers sharing and accessing an array of content, artefacts and information. These concepts are underpinned using time and space, because the usual constraints of time and space are transcended as learning through devices is no longer bound in physical spaces and timetables.

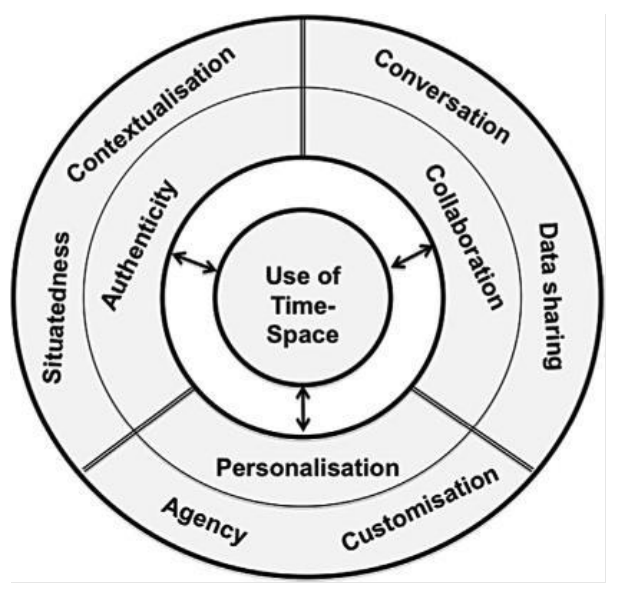

Figure 1. Framework comprising three distinctive characteristics of mobile learning experiences, with sub-scales. From Kearney et al. (2012, p. 8).

Kearney et al.'s (2012) framework is grounded in a socio-cultural perspective which 'suggests that learning is affected and modified by the tools used for learning' (p. 1). As Covid-19 pushed New Zealand students into learning through digital devices, and the purpose of this study was to investigate the intersection of technology and pedagogy for learning during the Covid-19 lockdown, we considered that Kearney et al.'s framework was an appropriate lens for investigating this phenomenon. Kearney et al. claim their framework 'foregrounds pedagogy rather than technology' (p. 2) and so provides a lens to analyse pedagogical approaches, teaching and learning activities and learning materials when using digital devices for learning. Furthermore, this framework was designed for the schooling sector.

Kearney et al's. (2012) framework was not designed for distance learning so literature from the distance education field needs to be considered as participants were forced into learning at a distance. According to European distance education pioneer Holmberg (2005) 'Distance 
education works' (p. 37), but the foremost condition needed for successful distance education is empathy, where empathy includes the student emotionally. Holmberg also considered that teachers need to develop relationships with students which along with empathy creates a feeling of belonging in the learning community which in turn supports motivation.

Moore (1993) described the distance between teachers and learners as 'transactional distance' which is pedagogical rather than geographical distance. This distance is determined by the variables of dialogue, structure and learner autonomy. Dialogue refers to valued interactions, and structure is whether an education programme is responsive to learner's needs. Learner autonomy is the extent to which the learner determines their goals and learning experiences. Moore's theory predates that of Kearney et al. (2012) and of online teaching, but aspects can be aligned with Kearney et al. Collaboration reflects dialogue, and personalisation and authenticity echo structure and learner autonomy. Both Kearney et al. and Moore emphasise the need for a socio-cultural approach and the potential of distance and online learning to provide student agency.

A key aspect of Kearney et al.'s (2012) framework is collaboration, but the need for this in distance online learning is debated with Anderson (2011) claiming most students enjoy the freedom to choose the time and pace of study that online learning affords. Participating in synchronous communities of learners restricts this independence. Yates and Thistoll (2019) concurred that not all students want to take part in an online community, but their existence provides security. Moore (2007) explains that interaction in distance learning involves learner to teacher, learner to content and learner to learner interaction. For some students, learner to teacher and learner to content interaction are sufficient and the active involvement of the teacher is preferred over collaborations among students.

However, these theories were developed for another time, not when the world's children were sent home from school to learn online. Distance education theories developed from a field of education where resources, platforms and teaching methods were carefully considered and took time to develop and curate. The situation created by Covid-19 has been proposed as 'emergency remote teaching' (Hodges et al., 2020) to distinguish it from high-quality online education. In addition, this was a temporary solution that returned to face-to-face learning when the emergency ended. 
There is already a growing body of literature related to education and Covid-19. The Asian Journal of Distance Education, Volume 15 (2020) devoted four articles to Covid-19. Bozkurt et al. (2020) reflect on and synthesise the impact of Covid-19 on schooling from 31 countries with a key theme being that education provided in a crisis should be developed from a 'pedagogy of care, affection and empathy' (p. 1) which echoes Holmberg's (2005) distance education theorising. Bozkurt \& Sharma (2020) agree with Hodges et al. (2020) that this situation should be named 'emergency remote education' so as not confuse education provided during Covid-19 with that of genuine distance education because "what people will remember will be bad examples from a time of crisis, and the years of efforts it has taken to prove the effectiveness of distance education can vanish' (p. ii). Other emerging themes include: the digital divide experienced by learners (Alavrez, 2020); the uneven impact on families, including inequity and social justice (Alavrez, 2020; Bozkurt et al., 2020); the need for more student centred-learning; and the need for educators be familiar with, and have some training in, online pedagogies (Bozkurt et al., 2020).

Despite the necessitated rush to put learning online there may be opportunities and possibilities that arise. Disruption to education is not limited to pandemics, natural disasters such as earthquakes, wars and civil conflicts can also interrupt schooling. We need to know how to serve students better during such disruptions and what we learn from the Covid-19 situation could inform schooling in the future. Therefore, this research explored senior high school students' experiences and perspectives of learning at home during the Covid-19 pandemic of 2020. The main objectives were to find out:

1. How New Zealand senior students experienced learning at home during the Covid-19 pandemic.

2. How the constructs of collaboration, personalisation and authenticity from Kearney et al.'s (2012) framework were experienced in this context.

3. How technology and pedagogy influenced the student experience.

\section{Methodology}

This research draws on an interpretive/constructivist paradigm because it aims to understand the complex world of lived experience from the point of view of those who live it (Schwandt, 1994). A constructivist paradigm is appropriate as this study hopes to gain an understanding of perceptions of participants about becoming online learners in the face of an international crisis. A mixed method design with mostly qualitative data was used and considered appropriate 
within a constructivist paradigm, as multiple realities and experiences may exist and we hope to gain insights as to how students experienced this phenomenon.

\section{Participants}

Students in their final two years of schooling, Years 12 and 13, from New Zealand high schools were invited to take part because people over 16 years can independently decide to take part in research and are likely to have well-formed opinions and the ability to articulate these. They were recruited through their schools with emails being sent to principals or deputy principals of schools with at least 100 students aged 16 years and over, which was 348 schools. Principals or the deputy principals were asked to forward the survey link to relevant students. Students were invited to enter a draw for a newly released PlayStation console to encourage participation. Sixty schools and 1,975 students from across New Zealand participated.

\section{Data collection}

Data was gathered through a questionnaire using the electronic tool Qualtrics. The researchers developed the questionnaire, which was peer reviewed, sent for expert opinion as to the suitability of the questions and trialled by students. Questions were both qualitative and quantitative with participants being asked about their perspectives of personalisation, authenticity and collaboration within the online pedagogy and digital tools they experienced. Open-ended questions were used to collect qualitative data with regards aspects of personalisation, authenticity and collaboration. Questions asked about what teachers did to help learning and favourite learning activities in order to ascertain if personalisation and authenticity occurred. Further questions specifically asked if learning was personalised through choice and whether collaboration occurred and its usefulness. Participants were asked about the most difficult aspects of studying under these conditions and which experiences they would like continued in a post-Covid model of education. (See Appendix 1 for full questionnaire).

\section{Data analysis}

Qualitative data were analysed using abductive reasoning drawing themes from the data and research literature. Abduction is an interpretivist approach and tries to report how individuals understand reality (Scott \& Morrison, 2005). Abductive reasoning is an epistemology of discovery which starts with an under-researched or new research problem (Moscoso, 2019) and therefore is particularly useful with new fields of research. Two coding methods were used: a priori codes, from Kearney et al.'s (2012) framework and codes that emerged from the data but did not fit within this framework. Emerging codes were developed through thematic analysis which allows patterns in the data to be noted. 
Quantitative data were analysed descriptively and integrated with the qualitative findings. Responses to the question of whether students felt, overall, that they learned more at home than they do at school were analysed in relation to participants' responses to the other questions to establish general tendencies. For this analysis participants were distinguished based on their responses to the other questions and the percentages of these were regarded that felt they learned less at home, the same at home, or more at home than they would in school. Formal correlational analysis was not possible due to the descriptive ordinal nature of the collected data.

\section{Ethical considerations}

All student participants were anonymous and over 16 years of age, they consented to participate by completing the survey. The identity of their schools is confidential to the researchers. As a form of reciprocity, the researchers offered schools with over 20 students responding a report containing both the generic results and results specific to their school. All schools participating were sent a copy of the findings. This research was carried out the ethical approval of the Human Ethics Committee of Victoria University of Wellington, New Zealand, ethical approval \#28604.

\section{Findings}

The findings are reported according to the constructs described by Kearney et al. (2012) and themes derived from the data. From the students' perspectives the experience of learning from home reflected the lenses described by Kearney et al. but in addition they described aspects important to their learning not evidenced in this framework. Therefore, these additional aspects of motivation and pedagogy were used to re-shape the framework to reflect the student experience of studying at home during the school closures of Covid-19.

\section{Learning from home}

A key experience of learning is the time spent learning and according to Reimers \& Schleicher (2020) is a reliable predictor of opportunity to learn. Therefore, we explored how much time students spent learning, whether they spent more or less time learning during Covid-19 lockdown than when at school and whether they learned more or less. While most students reported spending less time on schoolwork and learning less, a moderate but clear tendency was evident; that students who spent more time on schoolwork also felt they learned more or the same as they would have at school (Table 1). For example, of the students who spent less time studying at home, $66 \%$ felt they learned less at home than they would at school, whereas of the students who spent more time studying at home $35 \%$ felt they learned more. 
Table 1. Time students spent learning at home compared to at school in relation to how much they learned.

\begin{tabular}{|l|l|l|l|}
\hline $\begin{array}{l}\text { Time spent on } \\
\text { schoolwork at home }\end{array}$ & $\begin{array}{l}\text { Learned less } \\
\text { at home }\end{array}$ & $\begin{array}{l}\text { Learned about } \\
\text { same at home }\end{array}$ & $\begin{array}{l}\text { Learned more } \\
\text { at home }\end{array}$ \\
\hline Less time & $66 \%(648)$ & $21 \%(207)$ & $13 \%(128)$ \\
\hline Same amount of time & $37 \%(185)$ & $40 \%(203)$ & $23 \%(118)$ \\
\hline More time & $36 \%(174)$ & $29 \%(141)$ & $35 \%(171)$ \\
\hline
\end{tabular}

The numbers in the parentheses are the absolute numbers for the percentages provided.

\section{Personalisation}

The construct of personalisation as experienced by participants included: the ability to choose what to study within a subject; how to study; when to study beyond synchronous scheduled activities; and anytime access to resources. It was clear participants valued agency over the time and pace at which they learned. A key theme was independence and choice of when they devoted time to learning and how much time they would allocate to tasks and subjects. This enabled more time on creative subjects like art or 'Being able to plan my day to give more time to things I struggled in'.

Technology enabled this flexibility as teachers used platforms such as Google Classroom as repositories for learning materials or proprietary websites such as Education Perfect which could be accessed anytime: 'We were sent lots of online work that we were able to do at our own pace'. The ability to work on school-based NCEA assessments at their own pace, rather than in-class, was preferred and was seen as alleviating stress associated with completing qualifications. Participants valued this flexibility and would like it continued. Suggestions included spending less time in class, e.g. four days a week and the fifth self-directed learning (at home or at school) and that teachers continue to use technology to provide resources.

I would love to see lessons that provide us with what we need to know (1 or 2 a week). But after give us the opportunity to work away at it, that way I feel we have more free time and don't feel trapped in school which does not make it an enjoyable place for us at all. I believe lockdown gave us the chance to experience something new that we had no idea worked.

However, only a minority (10\%) preferred learning at home, the place of choice was school, but with more control over the use of time. Those who preferred home commented that school is stressful, has too many distractions such as disruptive students or they experienced bullying. 
Some students struggled to self-manage, feeling they 'had too much freedom. We had no one looking over what we actually worked on what was required'. Some recognised that lack of time management affected their motivation and learning and attributed this to "not having the routine of school, e.g. getting up early, having bell times and specified breaks'. Others linked their lack of self-management with a perceived increase in workload with 'teachers setting more work than we would have done at school' and a lack of co-ordination among subjects.

Some $(23 \%)$ participants had a choice of activities with $20 \%$ having some choice but $34 \%$ had no choice with teachers determining topics. This level of choice seemed to reflect usual practice with $70 \%$ of participants saying this was similar to that experienced in school.

A comparison between the amount of choice and their perceived amount of learning showed no evident tendency, indicating level of choice was not substantial to their experience of online learning. For example, in Table 2 , only $23 \%$ of students who had a choice in activities thought they learned more, while $49 \%$ who had choice thought they learned less.

Table 2. Amount of choice students had in relation to how much they learned at home.

\begin{tabular}{|l|l|l|l|}
\hline Choice in study & $\begin{array}{l}\text { Learned less } \\
\text { at home }\end{array}$ & $\begin{array}{l}\text { Learned about } \\
\text { same at home }\end{array}$ & $\begin{array}{l}\text { Learned more } \\
\text { at home }\end{array}$ \\
\hline No choice & $52 \%(403)$ & $27 \%(210)$ & $21 \%(159)$ \\
\hline Some choice & $53 \%(210)$ & $27 \%(107)$ & $20 \%(79)$ \\
\hline Own choice & $49 \%(353)$ & $29 \%(208)$ & $23 \%(164)$ \\
\hline
\end{tabular}

Individual personalisation in learning activities was not a significant feature reported by participants. The aspect of personalisation most appreciated was the flexible use of time.

\section{Authenticity}

Authenticity in Kearney et al. (2012) includes situatedness and contextualisation. Within the context of Covid-19 students were situated (through necessity) in their homes and neighbourhoods. While most reported learning activities which mirror those of the classroom, some were designed or adapted with students' contexts in mind with adaptations using resources within the home and using digital technology to approximate authentic experiences. Examples of using home resources included designing and cooking restaurant style meals for home economics, a lockdown challenge for outdoor education (including outdoor cooking, making a how-to video and risk assessment). Science teachers had students use household 
products to safely carry out chemistry experiments and 'My favourite activity was a series of practical experiments our physics teacher had designed for us to do with simple household objects'.

Some students enjoyed activities involving family members such as playing musical instruments together, photographing people within their 'bubble' or coaching siblings for physical education.

Completing my Level 3 portfolio for photography was my favourite virtual learning activity because I could take photos from home and video call my photography teacher and talk to her about how I was going ...

Digital technologies were used as a representation of authentic experiences: A virtual frog dissection for biology, using Zoom for a debate and using the computer camera to set the stage size for a solo drama performance were three notable examples.

A third type of authentic activity was integrating the context of Covid-19 lockdown into learning. This included the broader social context such as students developing news items about the effect of Covid-19 on the New Zealand economy for business studies, or a geography field study within students' neighbourhoods. Some activities drew on personal experiences such as reflecting on morning routines for creative writing or for physical education analysing whether they were exercising adequately to maximise their learning.

\section{Collaboration}

Aspects of collaboration reported were online conversations (learning and emotionally supportive) and collaborative learning activities. Students were asked to compare their experience of collaborating online at home with collaborating at school and most (53\%) preferred the familiarity of collaborating in class. Quantitative analysis identified a tendency that students who experienced online collaboration that was better than in-class also tended to feel that they learned more at home with $52 \%$ of those who thought collaboration was better than in class reporting that they learnt more at home, while $67 \%$ of those who thought the collaboration was less helpful than in class thought they learnt less at home (Table 3). This finding highlights the importance of effective collaboration. However, only a small number of participants $(\sim 10 \%)$ experienced online collaboration that was better than in-class collaboration. 
Table 3. Helpfulness of online collaboration in class in relation to how much they learned at home.

\begin{tabular}{|l|l|l|l|}
\hline $\begin{array}{l}\text { Helpfulness of online } \\
\text { collaboration with peers }\end{array}$ & $\begin{array}{l}\text { Learned less } \\
\text { at home }\end{array}$ & $\begin{array}{l}\text { Learned about } \\
\text { same at home }\end{array}$ & $\begin{array}{l}\text { Learned more } \\
\text { at home }\end{array}$ \\
\hline Less helpful than in class & $67 \%(710)$ & $22 \%(230)$ & $11 \%(113)$ \\
\hline The same & $34 \%(248)$ & $38 \%(272)$ & $28 \%(119)$ \\
\hline Better than in class & $24 \%(49)$ & $24 \%(49)$ & $52 \%(105)$ \\
\hline
\end{tabular}

Participants preferring online collaboration continued using social media in familiar ways through messaging and videoing platforms. For some 'Collaboration was better because it wasn't limited by teachers. We took our initiative to use separate mediums of communication to make sure we could still collaborate and solve problems ... this daily interaction with friends made the days more manageable'. Further reasons highlighted differing contexts and experiences. Those preferring online collaboration had teachers who used technology to facilitate small-group activities and they didn't experience time delays: 'Because everyone is at home, we can FaceTime each other and study together for the whole day without worrying about that the other person needs to go somewhere or do something'.

Key reasons for preferring in-class collaborative conversations were proximity to others (teachers and peers) and immediacy of support. Help is more accessible in class 'because you can just turn to your neighbour' and get an immediate answer and it was easier to attract the teacher's attention, whereas at home they had to find convenient times to message peers and teachers and wait for responses. The spontaneity of the classroom was preferred because school enables 'causal conversations' about schoolwork and to 'bounce ideas around'. Collaborating on unfamiliar platforms, e.g. Zoom 'felt unnatural' because only one person could talk and teachers dominated: 'No one talks on online classes except the teacher', classmates turned off videos and microphones and didn't participate: 'people tended to not speak (be muted) or show their face therefore it was hard to communicate or interact with them' and some students simply did not attend. Technical issues with internet access and/or equipment (e.g. no camera or microphone) were relatively rare with only $66(3 \%)$ participants mentioning these as a reason for preferring in-class collaboration. 
Synchronous collaboration was emotionally supportive because students could see friends and teachers and share concerns for general well-being. Two examples of teachers actively boosting morale were: 'Our teachers would play the guitar, while we would carry on doing the task that was set for us ... near the end of our class we would sometimes have a karaoke session' and 'Every Zoom call for history we had a dress up costume and a theme which made the calls more enjoyable'.

Collaborative learning activities were reported in physical education, drama and Kapa Haka (Māori performing arts), where students synchronised performances through platforms such as Zoom or Microsoft teams. One shared a detailed example:

In RE [religious education] class we were learning about secular humanists and atheist worldview. The task was to create a powerpoint or video with a group of people to explain a topic you were given. In my group of 3 we were given the worldview of secular humanists. As a group we created a powtoon to show what is it, who believes in it and how it is implicated in today's society ... I really enjoyed this task as it felt like we were in class collaborating together, even though we were in our own homes.

Collaboration was an important aspect of the students' experience of learning at home.

\section{Motivation}

When asked about the hardest part of learning at home, $39 \%$ cited 'motivation'. This lack of motivation was linked to contextual issues which included: family obligations, e.g. looking after siblings or helping out at home or on the farm; distractions like Netflix or online shopping; inaccessibility of teacher or peer help; lack of extrinsic consequences; and the lack of distinction between home and school. For some, 'the hardest part of working from home was finding the motivation to do schoolwork during the uncertainty of the state of world'. Without the extrinsic drivers of school, routine, consequences, resources and easy access to teacher and peer support, many students reported being unable to find the intrinsic motivation to study. Timing choice was also a demotivator. Faced with teachers giving out work at the beginning of each week, $5 \%$ of respondents reported being overwhelmed or not having time management skills to independently work through their tasks. Being provided with a timetable, or creating one themselves, appeared to make little difference to motivation and time management. 
While most participants reported less than 6 hours of scheduled classes a week, for some this was not the case and $219(11 \%)$ reported having to attend over 18 hours of online lessons each week. The extensive synchronous use of technology which appeared to transpose the routines and practices from the classroom environment was not motivating for students. For example: [There was a] lack of motivation to get some work done as it was easy to not do anything. It was difficult to sit in front of a screen for an hour at a time, for 5 hours a day just listening to a teacher talk with not much interaction at times.

Some students reported studying up to 9 hours each day because, following Zoom calls, they 'had all this work to do after school, meaning we were doing schoolwork all day and night'. Sporadic scheduling was problematic for some who found it hard 'remembering the times that the video calls were happening' or 'waking up for the early Teams calls'.

Only $1 \%$ of participants described technology access in 'demotivating' terms such as inadequate $\mathrm{Wi}-\mathrm{Fi}$ or inaccessible apps. The predominant motivating or de-motivating factor of technology was its use in gaining support through communicating with teachers. Some students reported feeling uncomfortable asking questions in front of a class on Zoom, through email or in a call. They were demotivated when there was a delay in a teacher response and sometimes 'it seemed too much effort to ask the question then wait for a reply'.

When asked about effective and helpful strategies that teachers implemented, approximately $2 \%$ of respondents specifically described strategies in terms of being 'motivating' or 'motivational'. When describing successful learning at home, 5.5\% described teachers using technology to be helpful, motivating and supportive. Motivation was equated with supportive pedagogies including teachers personally checking in with them, giving feedback on work, and personal phone calls or phoning parents. Students reported being motivated when teachers used communication tools and curation platforms (Google, Education Perfect) for personal academic support. Also motivating were when teachers offered 'loads of resources that catered to a variety of learning preferences', made expectations clear, 'gave us time limits and due dates', and were supportive such as: 'reassured me that any work is better than no work', gave 'private lessons' and 'offer[ed] lots and lots of encouragement'.

\section{Pedagogy}

A range of pedagogical practices were identified when participants described their favourite learning activities: direct instruction, receiving feedback, multimedia resources, class 
discussions, clear communication, interactive activities and gamification. Direct instruction was considered an efficient way to develop academic knowledge by those who were time conscious:

Just being able to listen to the teacher and taking down notes in a lecture-styled way. Although some teachers worried it would be too boring, it was more straight to the point and less time consuming than 'active activities'.

Watching movies, YouTube or teacher-made recordings were preferred activities because they provided visual information, were different to text-based activities, could be accessed multiple times and could involve family members, for example, watching and comparing sitcoms across the decades with their father. Others preferred interactive activities, such as collaborating through gamification or virtual whiteboards and creating products:

Making a stop-motion on the human digestive system. We had to put all our knowledge of the human digestive together into a stop-motion video. This video was helpful for our assessment where we had to compare the wolf, cow and human digestive system. I enjoyed it because we were able to be creative about how we did the stop-motion.

Well-managed online class discussions enabled participation, and to some participants this seemed more orderly than in-class discussions because they weren't talking over each other and teachers managed student engagement:

I enjoyed maths meetups the most because I felt that I learnt more in that class than my others, and because the teacher was actively engaging us all and it felt more like one-on-one learning rather than group teaching.

Clarity, organisation and easy access to the resources were important: Knowing what to do, how and when it had to be completed contributed to favourite learning activities. Teacher-made or commercial videos were useful for immediate learning, and for revisiting topics: 'Maths explanations...as it showed all the necessary steps in solving the problem, and she explained it clearly. It was easy as I could pause and go anywhere into the video if needed and understand it in my own pace'. It seems some teachers had particularly well curated learning management sites in which students accessed content and information.

Gamification which included an element of competition either between peers or against themselves was the most popular pedagogical approach. Examples include online quizzes (e.g. 
Kahoot), proprietary products which incorporate gamification (e.g. Education Perfect), and teacher developed competitive activities such as online scavenger hunts, bingo, an online bridge building competition in physics and physical challenges for physical education. Reasons these were enjoyed included being fun and supportive social interaction, and they provided feedback on academic progress:

Doing a Kahoot with our class on zoom. It was fun to play this with everyone and to quiz ourselves on what we know in a fun way! It was nice to have fun during a stressful time and being able to do this with everyone.

Some preferred activities different from usual school activities, while others enjoyed what was familiar. Not all favourite activities were aimed at academic or curriculum related goals. Participants also identified activities that supported their social and emotional wellbeing such as group competitions.

\section{Discussion}

Participants in this study were in a unique educational situation, they were not distance students who expected to study online unknown to each other. They had been together in class since the start of the academic year, approximately seven weeks before Covid-19 school closures, some were in schools which were virtually paperless, with extensive use of digital tools for learning, others had less experience prior to lockdown. Constructs in Kearney et al.'s (2012) framework were reflected in participants experience of learning in this context, but motivation and pedagogical approaches were also important aspects of this experience. In light of these additional aspects Kearney et al.'s framework has been adapted to reflect participants experience of emergency online learning at home (Figure 2).

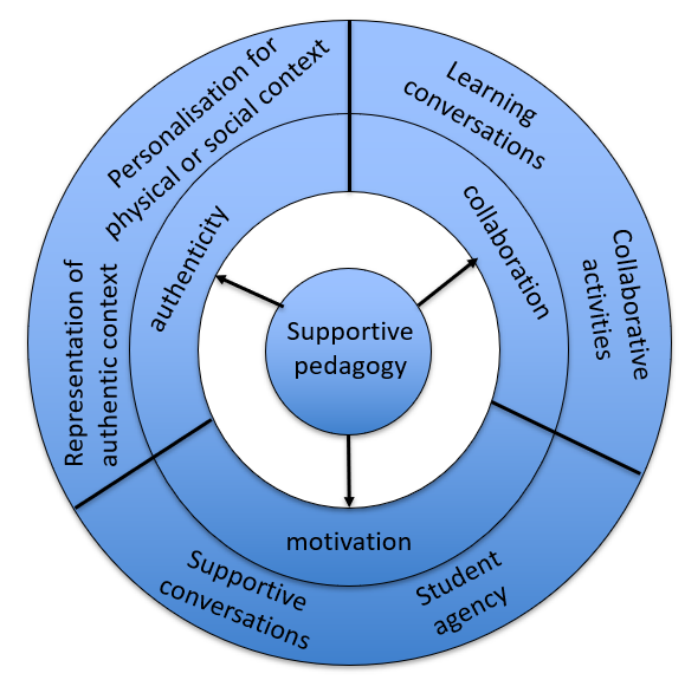

Figure 2. Technology mediated supportive pedagogy for emergency context learning at home. 
The authenticity construct in Kearney et al.'s (2012) framework for using mobile devices in learning is not clearly defined. It consists of situatedness and contextualisation and is also described as 'contextualised, participatory, situated learning' (p. 14). Later, Kearney et al. (2015) surveyed teachers and explored three aspects of authenticity: setting, task and tool and concluded that the construct can be open to interpretation, and Burden and Kearney (2016) further developed the construct to include three aspects: context which includes situatedness and participation; personal relevance; and planning design. The authenticity construct outlined by Kearney et al. (2012) did not align well with students experience of learning during school closures of Covid-19, perhaps because students were not mobile and this study focused on learning in one context, their home. However, authenticity was an important theme and from the students' responses we created two important sub-components: representation of authentic experience through digital tools or home resources; and learning activities which drew on the context of a pandemic lockdown.

Collaboration in Kearney et al.'s (2012) framework includes conversations and data sharing. Collaboration in this study replicated conversational aspects of this framework through conversations between students and between students and a teacher, but also identified were collaborative activities whereby students worked together. Collaborative activities were mediated through technology, but they did tend to replicate collaboration which occurs in the face-to-face schooling context. Vygotsky (1978) emphasised the need for social interaction for cognitive development and while most participants stated a preference for the proximity of inclass collaboration examples of effective online collaboration were shared. Means and approaches for using technology to establish effective online collaboration have remained elusive (Sun, 2016) but for participants in this study the effective use of technology to enable synchronous, small group learning conversations and collaborative learning activities had a positive influence on perceived learning. Therefore, learning conversations and collaborative learning activities are sub-components of the construct of collaboration.

Motivation (or lack of) was an important theme and an aspect not identified by Kearney et al. (2012). Participants were learning without school structures, and many struggled to find motivation to study without the extrinsic drivers of school routines - a context differing from that envisioned by Kearney et al.. The critical role of motivation to engage in distance learning has long been recognised $(\mathrm{Ng}, 2019)$ but with nearly $40 \%$ of participants citing they lacked motivation to study at home this aspect needed more cognisance by teachers. Motivational 
strategies were using technology for supportive personal conversations, providing feedback on work and having clear expectations supporting Simpson's (2008) model of proactive motivational support. Also motivating were course resources and specific activities which aligns with the notion of distributed motivation whereby motivation lies not just with the student but also with learning materials, multimedia technologies and learning platforms $(\mathrm{Ng}$, 2019). The significance of motivation is reflected in its inclusion in the revised framework (Figure 2). The importance of supportive conversations with teachers, and the facilitation of student agency through motivational resources and having clear expectations are reflected in the sub-components.

Kearney et al. (2012) defined personalisation as including contextualisation and agency, but as with authenticity, personalisation is not clearly defined in the literature and overlaps with authenticity and motivation. Personalisation can occur across a continuum from complete individualisation to providing some choice, and includes variables such as the learning environment, engagement, choice and agency (Waldrip et al., 2016). There was little evidence from the students' perspective that learning activities were customised for individual learners, but contextualisation did provide authentic experiences. The strong agentic component reported focused on having responsibility for their use of time, which occurred due to the context of Covid-19 lockdown, rather than as a deliberate pedagogical approach. Personalisation was not a significant standalone theme in this study and is integrated across authenticity and motivation in the revised framework (Figure 2).

At the centre of Kearney et al.'s framework (2012) was the use of time and space. This is an important aspect of flexible, mobile learning, when traditional physical and timing constraints of formal learning are loosened in the digital age to enable student-centred education (Starkey, 2019). However, while participants experienced flexibility with timing of learning, the space aspect was limited to learning at home and through digital devices. Space and time were not at the centre of their experiences. Instead, two priorities underpinned participants experience of learning at home: academic progress towards qualifications and their social and emotional wellbeing. Therefore, a framework of learning at home for senior high school students should have supportive pedagogy at the centre.

Half of the students reported they learnt more when attending school, a finding that aligns with a recent Covid-19 report (Reimers \& Schleicher, 2020). Attending school was favoured over 
learning at home for a slight majority of participants which appeared to be due to familiarity of the learning environment, routines, expectations, teacher presence, and being with friends. Participants valued familiar pedagogical practices whereby teachers used digital tools and resources to replicate or approximate learning activities experienced at school.

The idea of supportive pedagogy has been pervasive throughout all aspects of this study and has implications for each of the three characteristics in the revised framework. It is important to recognise that online learning is not the same as classroom learning and, therefore, effective pedagogical approaches differ (Moore, 2007). The physical environment and distractions differ, learning is not time-bound beyond scheduled meetings, students cannot gain immediate clarifications or feedback, and teachers have less observational or incidental information to identify, and be responsive to, student well-being issues. Additionally, the introduction of new ways of learning can be stressful and supportive pedagogies enable students to make academic progress and reduce stress. Supportive pedagogies included clear instructions, guidance on managing time, empathetic, well-managed discussions, multiple ways of checking learning progress, multimedia resources, fun collaborative activities, authentic experiences, and providing a structure that encouraged motivation while also giving flexibility. For example, the independent use of time was supported by teachers who curated learning management systems to provide clear plans. An important first step in supportive pedagogy is preparing students to be independent and to take responsibility for their own learning.

Supportive pedagogy aligns with Holmberg's (2005) idea of empathy and Noddings (1984) 'ethic of care' whereby pedagogical actions are motivated by the needs of students. Supportive pedagogy is cognisant of students' individual situations and provides support for their wellbeing, which is more complex when interactions are mediated by technology. Providing emotional support is particularly relevant in emergency situations and crises, which students may experience as stressful and where their normal support networks may be limited. A second aspect overlaps with motivation in that supportive pedagogy helps students organise their time and stay focused in the face of distractions.

\section{Conclusion}

This research sought to find out how New Zealand senior high school students experienced learning at home during the Covid-19 pandemic, how the constructs of collaboration, personalisation and authenticity from Kearney et al. (2012) were experienced and how 
technology and pedagogy influenced that experience. Aspects of Kearney et al.'s framework were evident for learning in this context, however, more important were teachers providing supportive pedagogies to enhance the students' motivation to study. Students had greater agency and flexibility over their use of time which was appreciated by some, but others lacked the skills to manage this productively. In this context students valued continuing to make academic progress towards qualifications and maintaining their social and emotional wellbeing. Supportive pedagogy through effective use of technology enabled motivation, collaboration and authentic learning activities which enhanced the students' experience of learning in this context. The framework of supportive pedagogy mediated by technology presented from this research could be applied during future emergency events which require school closures.

\section{References}

Alvarez, A. (2020). The phenomenon of learning at a distance through emergency remote teaching amidst the pandemic crisis. Asian Journal of Distance Education, 15(1), 144-153. DOI: $10.5281 /$ zenodo.3881529

Anderson, H. (2011). How to increase student retention and success: A systematic, evidenceinformed approach. Retrieved from https://akoaotearoa.ac.nz/download/ng/file/group3300/how-toincrease-student-retention-and-success.pdf

Bozkurt, A. \& Sharma, R. (2020). Emergency remote teaching in a time of global crisis due to CoronaVirus pandemic. Asian Journal of Distance Education, 15(1), i-vi. DOI: 10.5281/zenodo.3778083

Bozkurt, A. Jung, I., Xiao, J., Vladimirschi, V., Schuwer, R., Egorov, G., Lambert, S., AlFreih, M., Pete, J., Olcott, D., Rodes, V., Aranciaga, I., Bali, M., Alvarez, a., Roberts, J., Pazurek, A., Raffaghelli, J., Panagiotou, N.,..... Paskevicius, M. (2020). A global outlook to the interruption of education due to COVID-19 Pandemic: Navigating in a time of uncertainty and crisis. Asian Journal of Distance Education, 15(1), 1-126. DOI: 10.5281/zenodo.3878572

Burden K., \& Kearney M. (2016). Conceptualising Authentic Mobile Learning. In D. Churchill, J. Lu, T. Chiu, \& B. Fox (Eds.) Mobile Learning Design. Lecture Notes in Educational Technology. Springer, Singapore. https://doi.org/10.1007/978-981-10-00270_2

Education Review Office (2020). Covid-19: Learning in Lockdown. Wellington: Author. Retrieved from https://www.ero.govt.nz/publications/covid-19-learning-in-lockdown 
Hipkins, R., Johnston, M., \& Sheehan, M. (2016). NCEA in context. Wellington: New Zealand Council for Educational Research. ISBN:978-0-947509-27-9

Hodges, C., Moore, S., Lockee, B., Trust, T., \& Bond, A. (2020). The Difference Between Emergency Remote Teaching and Online Learning. EDUCAUSE Review. Retrieved from https://er.educause.edu/articles/2020/3/the-difference-between-emergency-remoteteaching-and-online-learning

Holmberg, B. (2005). The evolution, principles and practices of distance education. Oldenburg: BIS-Verlag Carl von Ossietzky Universitat. Retrieved from https://uol.de/fileadmin/user_upload/c31/master/mde/download/asfvolume11_eBook.pdf

Kearney, M., Schuck, S., Burden, K., \& Aubusson, P. (2012). Viewing mobile learning from a pedagogical perspective. Research in Learning Technology, 20. https://doi.org/10.3402/rlt.v20i0.14406

Kearney, M., Burden, K., \& Rai, T. (2015). Investigating teachers' adoption of signature mobile pedagogies. Computers \& Education, 80, 48-57. ISSN 0360-1315, https://doi.org/10.1016/j.compedu.2014.08.009.

Moore, M. G. (1993). Theory of transactional distance. In Keegan, D. (Ed.), Theoretical principles of distance education (pp. 22-38). New York, NY: Routledge. ISBN-0-41508942-5

Moore, M. (2007). The theory of transactional distance. In M. Moore (Ed.), The handbook of distance education ( $2^{\text {nd }}$ ed., pp. 32-46). Mahwah, NJ: Lawrence Erlbaum. ISBN:9781315296135

Moscoso, J.N. (2019). Abductive reasoning: A contribution to knowledge creation in education. Cadernos de Pesquisa, 49(171), 308-329, https://doi. org/10.1590/198053145255

Ng, C. (2019). Shifting the focus from motivated learners to motivating distributed environments: a review of 40 years of published motivation research in Distance Education. Distance Education, 40(4), 469-496, DOI: 10.1080/01587919.2019.1681892

Noddings, N. (1984). Caring: A Feminine Approach to Ethics and Moral Education. Berkeley: University of California Press. ISBN: 9780520057470

Reimers, F, \& Schleicher, A. (2020). A framework to guide an education response to the COVID-19 Pandemic of 2020. OECD. Retrieved from http://www.oecd.org/education/

Schwandt, T. A. (1994). Constructivist, interpretivist approaches to human inquiry. In N. K. Denzin \& Y. S. Lincoln (Eds.), Handbook of qualitative research (p. 118-137). Thousand Oaks, Calif: Sage Publications. 
Scott, D., \& Morrison, M. (2005). Key ideas in educational research. London: A\&C Black. ISBN: 9780826479907

Selwyn, N., Nemorin, S., Bulfin, S., \& Johnson, N. (2017) Left to their own devices: the everyday realities of one-to-one classrooms. Oxford Review of Education, 43(3), 289-310. ISSN 0305-4985 DOI: 10.1080/03054985.2017.1305047

Simpson, O. (2008). Motivating learners in open and distance learning: Do we need a new theory of learner support? Open Learning: The Journal of Open and Distance Learning, 23, 159-170. doi:http:// dx.doi.org/10.1080/02680510802419979

Starkey, L. (2019). Three dimensions of student-centred education: a framework for policy and practice. Critical Studies in Education, 60(3), 375-390. doi:10.1080/17508487.2017.1281829

Starkey, L. (2020). A review of research exploring teacher preparation for the digital age. Cambridge Journal of Education. 50 (1), 37-50. doi:10.1080/0305764X.2019.1625867

Sun, J. (2016). Multi-dimensional alignment between online instruction and course technology: A learner-centered perspective. Computers \& Education, 101, 102-114. DOI:10.1016/j.compedu.2016.06.003

Vygotsky, L. S. (1978). Mind in Society: The development of higher psychological processes. Cambridge, MA: Harvard University Press. ISBN 9780674576292

Waldrip, B., Yu, J. J., \& Prain, V. (2016). Validation of a model of personalised learning. Learning Environments Research, 19(2), 169-180. ISSN:ISSN-1387-1579

Wylie, C. (2012). Vital connections: Why we need more than self-managing schools. Wellington: NZCER press. ISBN: 978-1-927151-57-0

Yates, A., \& Thistoll, T. (2019). The student experience in an online tertiary enabling course. In D. Singh \& M. Makhanya (Eds.) Essays in online education: A global perspective (pp.4759). UNISA Press: Pretoria, South Africa. ISBN 978-1-77615-051-9. 
Appendix 1: Survey questions

1. What is your year level? $12 / 13$

2. What is the name of your school?

3. What number of timetabled virtual classes were you expected to attend each week? 0 , $1-6,7-12,13-18,>18$

4. How much time did you spend each day engaged in learning at home? $<1$ hour, 1 to 2 hours, 2 to 3 hours, 3-4 hours. 4 hours, other.

5. Is this more or less time than you would normally spend engaged in learning at school? More/about the same/less

6. Do you think you learn more when studying at home than studying at school? Y/N/about the same

7. What are three things your teachers did that helped you to successfully learn at home?

8. What has been your favourite virtual learning activity? Describe the activity and why you enjoyed it.

9. How helpful was online collaboration with your peers for your learning?

a. Better than in class collaboration, about the same, I learn more when collaborating in class. (explain why for those answering better or worse)

Thinking about the subject that you enjoyed most when learning at home:

10. Name the subject:

11. How much choice did you have in how you studied that subject?

12. Was the level of choice similar to what you have when learning at school? [more/similar/less]

13. Did your teacher give everyone in the class the same learning activities?

a. everyone did the same

b. we could choose between set activities

c. we were given different activities.

d. we were given the same activity but could choose what we studied within that task.

14. What was the hardest part about learning at home?

15. What is something that you did as a virtual learner that you hope you will be able to continue back at school?

16. Please add any other comments you would like to make that could help shape how learning happens in the future at your school. 